\title{
SEKOLAH SEHAT SEBAGAI UPAYA PENINGKATAN KESEHATAN ANAK USIA SEKOLAH DI KECAMATAN SINGAPARNA KABUPATEN TASIKMALAYA TAHUN 2017
}

\author{
OLEH : \\ Teni Supriyani, S.Si, M.KM \\ Neni Ambar Alawiah, AMKG
}

\section{A. DASAR PEMIKIRAN}

Undang-undang Republik Indonesia nomor 20 tahun 2003 tentang Sistem Pendidikan Nasional menyatakan bahwa pendidikan merupakan suatu usaha sadar dan terencana untuk mewujudkan suasana belajar dan proses pembelajaran agar peserta didik secara aktif mengembangkan potensi dirinya. Untuk membuat suasana belajar yang aktif dan efektif, salah satu hal yang harus diperhatikan adalah kondisi lingkungan sekolah yang merupakan tempat diselenggarakannya proses belajar mengajar secara formal.

Lingkungan sekolah yang kondusif sangat penting dan diperlukan agar tercipta proses pembelajaran yang bermutu. Dalam Undang-undang nomor 36 tahun 2009 tentang kesehatan, di pasal 79 disebutkan bahwa kesehatan sekolah diselenggarakan untuk meningkatkan kemampuan hidup sehat peserta didik dalam lingkungan hidup sehat sehingga peserta didik dapat belajar, tumbuh, dan berkembang secara harmonis dan setinggi-tingginya menjadi sumber daya manusia yang berkualitas.

Peraturan bersama antara Menteri Pendidikan dan Kebudayaan Republik Indonesia, Menteri Kesehatan Republik Indonesia, Menteri Agama Republik Indonesia, dan Menteri Dalam Negeri Republik Indonesia nomor 6/X/PB/2014, nomor 73 tahun 2014, nomor 41 tahun 2014, nomor 81 tahun 2014 tentang Pembinaan dan Pengembangan Usaha
Kesehatan Sekolah/Madrasah menyebutkan bahwa Usaha Kesehatan Sekolah/Madrasah (UKS/M) merupakan kegiatan yang dilakukan untuk meningkatkan kesehatan anak usia sekolah pada setiap jalur, jenis, dan jenjang pendidikan. UKS/M ini bertujuan untuk meningkatkan mutu pendidikan dan prestasi belajar peserta didik dengan meningkatkan perilaku hidup bersih dan sehat serta menciptakan lingkungan pendidikan yang sehat, sehingga memungkinkan pertumbuhan dan pekembangan yang harmonis peserta didik.

Dalam praktiknya, kegiatan pokok UKS/M ini dilaksanakan melalui Trias UKS/M, yang terdiri dari pendidikan kesehatan, pelayanan kesehatan, dan pembinaan lingkungan sekolah sehat. Pembinaan lingkungan sekolah sehat meliputi beberapa hal, yaitu:

1. Pelaksanaan kebersihan, keindahan, kenyamanan, ketertiban, keamanan, kerindangan, dan kekeluargaan $(7 \mathrm{~K})$

2. Pembinaan dan pemeliharaan kesehatan lingkungan termasuk bebas asap rokok, pornografi, narkotika psikotropika dan zat adiktif lainnya (NAPZA), dan kekerasan

3. Pembinaan kerja sama antar masyarakat sekolah

Sekolah sehat meliputi beberapa dimensi penilaian, antara lain kesehatan fisik, kesehatan sosial, dan kesehatan psikis (Hijjang, 2009). Sekolah sehat adalah sekolah yang secara berkesinambungan terus mengupayakan 
dan menguatkan kapasitasnya sebagai tempat yang sehat untuk tinggal, belajar, dan bekerja. Sekolah sehat merupakan sekolah yang berupaya untuk menciptakan wilayah yang sehat dan aman, yang menerapkan kebijakan dan praktik promosi kesehatan (Depkes, 2004).

Lingkungan sekolah yang sehat dan kondusif sangat diperlukan agar tercipta proses pembelajaran yang bermutu. Pemberian pengetahuan dan pembentukan kesadaran tentang perilaku hidup bersih dan sehat di lingkungan sekolah akan lebih efektif ketika dilakukan pada siswa sejak di bangku sekolah dasar, sehingga

menjadi sebuah kebiasaan sejak dini. Dengan ditanamkan sejak di sekolah dasar juga diharapkan menjadi pembiasaan ketika berada di luar lingkungan sekolah.

Untuk mewujudkan sekolah/madrasah sehat, diperlukan upaya-upaya yang menyeluruh. Dalam kegiatan pembinaan sekolah sehat STIKes Respati di kawasan kerja Puskesmas Singaparna tahun 2017, upaya yang dilakukan merujuk kepada beberapa sumber seperti kebijakan tentang sekolah sehat serta buku saku dan petunjuk teknis pelaksanaan sekolah/madrasah sehat, yang kemudian disesuaikan dengan sumber daya dan kemampuan yang tersedia untuk pembinaan.

\section{B. TUJUAN}

\section{Tujuan Umum:}

Menciptakan lingkungan sekolah yang sehat sehingga derajat kesehatan warga sekolah meningkat dan penyelenggaraan kegiatan belajar mengajar menjadi lebih efektif

\section{Tujuan Khusus:}

a. Melakukan pemantauan kondisi lingkungan sekolah

b. Melakukan pemeriksaan dan penilaian kondisi lingkungan sekolah

c. Melakukan diskusi tentang capaian sekolah sehat

d. Merintis kegiatan sekolah sehat agar menjadi kegiatan berkelanjutan

\section{BENTUK KEGIATAN}

Kegiatan yang dilakukan dibagi menjadi tiga bagian, yaitu pemantauan, pemeriksaan dan penilaian, serta diskusi.

\section{Pemantauan}

Pemantauan dilakukan untuk melihat kondisi awal lingkungan sekolah. Pemantauan ini dilakukan di setiap ruang yang ada di lingkungan sekolah, meliputi:

a. Ruang kelas

b. Ruang guru

c. Ruang kepala sekolah

d. Ruang perpustakaan

e. Ruang UKS yang meliputi program, kelengkapan, dan pemanfaatannya

f. Sarana sanitasi pendukung PHBS (Perilaku Hidup Bersih dan Sehat) sekolah, yang terdiri dari jamban sehat, kantin sehat, dan sarana cuci tangan 
2. Pemeriksaan dan penilaian

Setelah pemantauan, dilakukan kegiatan pemeriksaan lebih rinci kondisi masing-masing ruang. Pemeriksaan ruang-ruang tersebut terkait dengan aspek kebersihan, kerapian, kesehatan lingkungan, serta ketersediaan sarana pendukung PHBS sekolah.

Pemeriksaan dan penilaian ini bertujuan untuk melihat kondisi awal lingkungan sekolah, sehingga selanjutnya dapat dijadikan dasar dalam menerapkan konsep sekolah sehat. Dari pemeriksaan dan penilaian diharapkan dapat diketahui poin apa saja yang masih harus ditingkatkan, belum sesuai, atau bahkan kondisinya masih sangat kurang. Pemeriksaan dan penilaian menggunakan instrumen seperti terlampir.

3. Diskusi dan Evaluasi

Pasca pemeriksaan dan penilaian kondisi lingkungan sekolah, dilakukan diskusi dan evaluasi dengan pihak sekolah. Diskusi ini melibatkan beberapa pihak seperti dari kepala sekolah, guru, dan beberapa siswa. Dengan adanya diskusi ini diharapkan ada tindak lanjut dari hasil pemeriksaan dan penilaian untuk meningkatkan capaian sekolah sehat yang diharapkan.

\section{SASARAN}

Sekolah dasar yang ada di Kecamatan Singaparna, khususnya yang berada di 5 desa yaitu Desa Sukamulya, Desa Singaparna, Desa Cintaraja, Desa Cikunir, dan Desa Cikadongdong.

E. TEMPAT DAN WAKTU

1. Kegiatan pembinaan sekolah sehat dilaksanakan di 10 tempat, yaitu:

a. SDN 2 Cipakat

b. SDIT Mutiara Sahara

c. SDN 1 Singaparna

d. SDN 2 Singaparna

e. SDN 1 Cintaraja

f. SDN 2 Cintaraja

g. SDN Cikunir 1

h. SDN Anggaraja

i. SDN Cikadongdong

j. SDN Mekarahayu

2. Waktu pelaksanaan pembinaan sekolah sehat dimulai Bulan November s/d Februari 2018

\section{F. KEPANITIAAN}

1. Teni Supriyani, S.Si., M.K.M (Dosen STIKes RespatI)

2. Neni Ambar Alawiah, AMKG (Puskesmas Singaparna)

3. Mahasiswa Program Studi S1 Kesehatan masyarakat 


\section{G. HASIL KEGIATAN}

Hasil Pemeriksaan Dan Penilaian Sekolah Sehat (SD/MI/Sederajat)

Di Kecamatan Singaparna

\begin{tabular}{|l|l|c|c|}
\hline \multicolumn{1}{|c|}{ Desa } & \multicolumn{1}{|c|}{ Nama Sekolah } & Total Nilai & Peringkat \\
\hline \multirow{2}{*}{ Sukamulya } & 1. SDN 2 Cipakat & 4.136 & 9 \\
\cline { 2 - 4 } & 2. SDN Mutiara Sahara & 5.624 & 2 \\
\hline \multirow{3}{*}{ Singaparna } & 3. SDN 1 Singaparna & $5.349,5$ & 3 \\
\cline { 2 - 4 } & 4. SDN 2 Singaparna & $5.762,5$ & 1 \\
\hline \multirow{2}{*}{ Cintaraja } & 5. SDN 1 Cintaraja & $4.716,5$ & 5 \\
\cline { 2 - 4 } & 6. SDN 2 Cintaraja & $3.850,5$ & 10 \\
\hline \multirow{2}{*}{ Cikunir } & 7. SDN Cikunir 1 & 4.675 & 6 \\
\cline { 2 - 4 } & 8. SDN Anggaraja & 4.175 & 8 \\
\hline Cikadongdong & 9. SDN Cikadongdong & 4.338 & 7 \\
\cline { 2 - 4 } & 10. SDN Mekarahayu & 5.112 & 4 \\
\hline
\end{tabular}

\section{H. DAFTAR PUSTAKA}

Departemen Kesehatan Republik Indonesia. 2004. Usaha Kesehatan Sekolah dalam Gambar.

Hijjang, P. 2009. Perintisan Model Sekolah Sehat di Sekolah Dasar Sebagai Upaya Peningkatan Kesehatan Warga Sekolah di Kabupaten Pangkep Provinsi Sulawesi Selatan.

Presiden Republik Indonesia. 2003. Undang-undang Republik Indonesia nomor 20 tahun 2003 tentang Sistem Pendidikan Nasional.

Presiden Republik Indonesia. 2009. Undang-undang Republik Indonesia nomor 36 tahun 2009 tentang Kesehatan.

\section{DOKUMENTASI}

Gambar 1. Pemeriksaan Ruang Perpustakaan

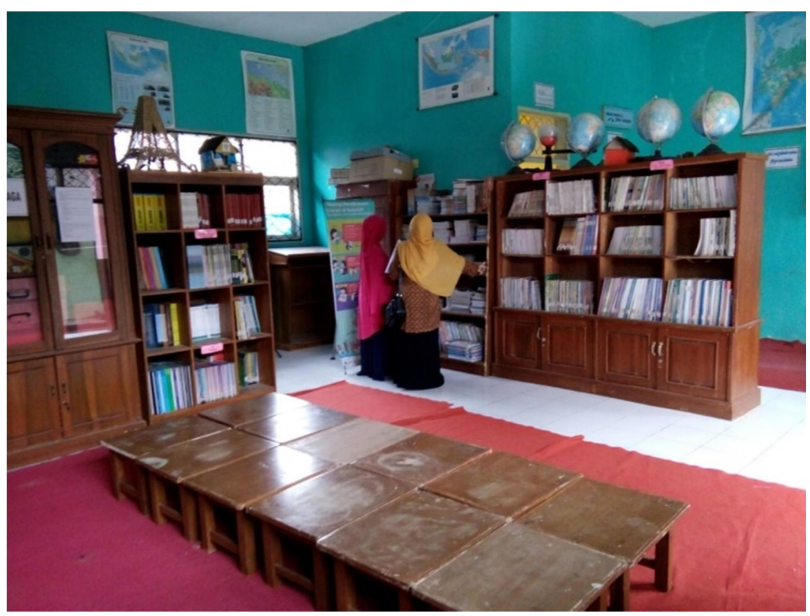




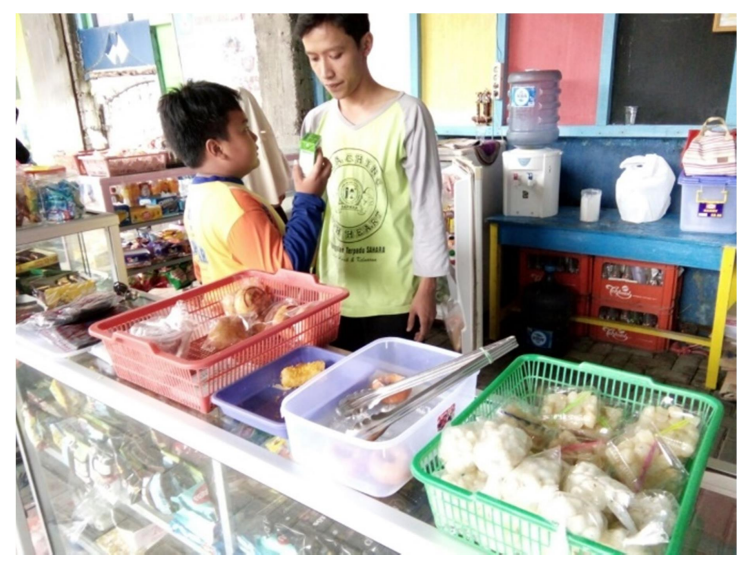

Gambar 2. Pemeriksaan Kantin Sehat

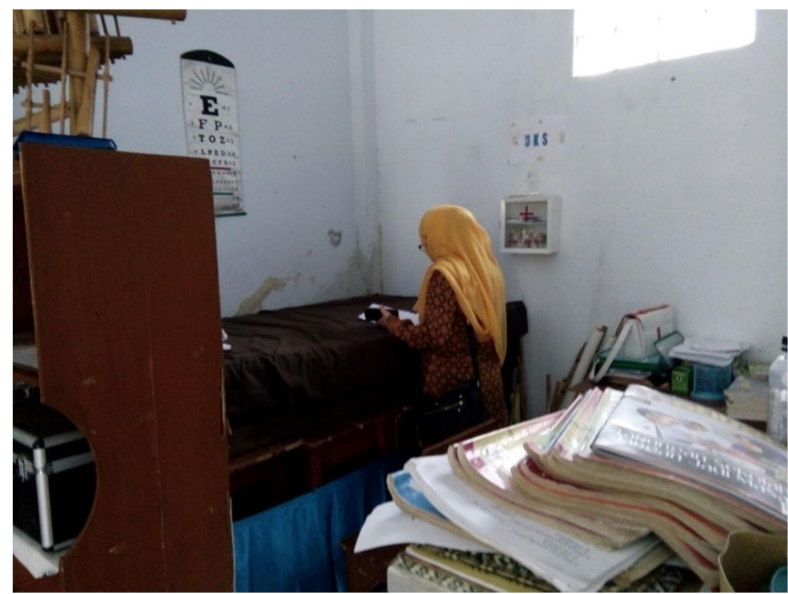

Gambar 3. Pemeriksaan Ruang UKS

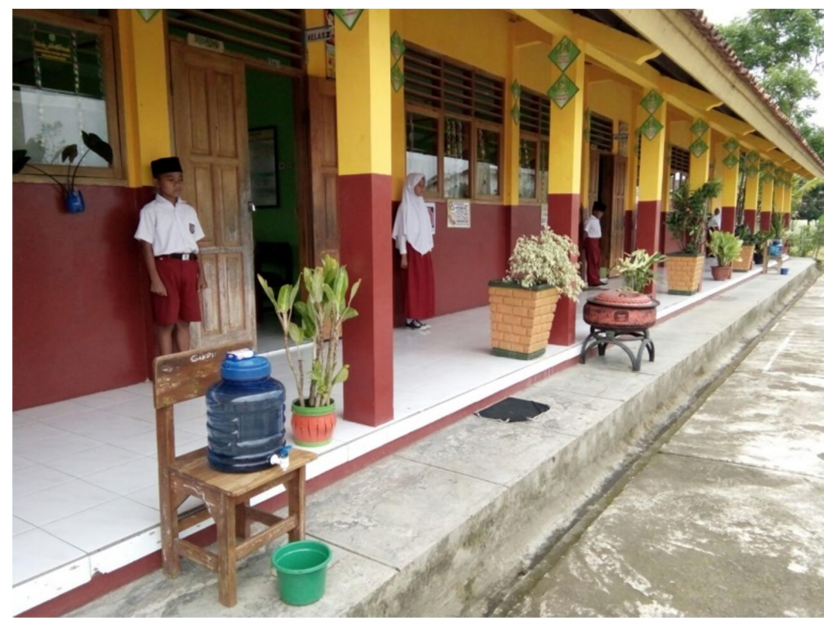

Gambar 4. Kondisi lingkungan salah satu sekolah 


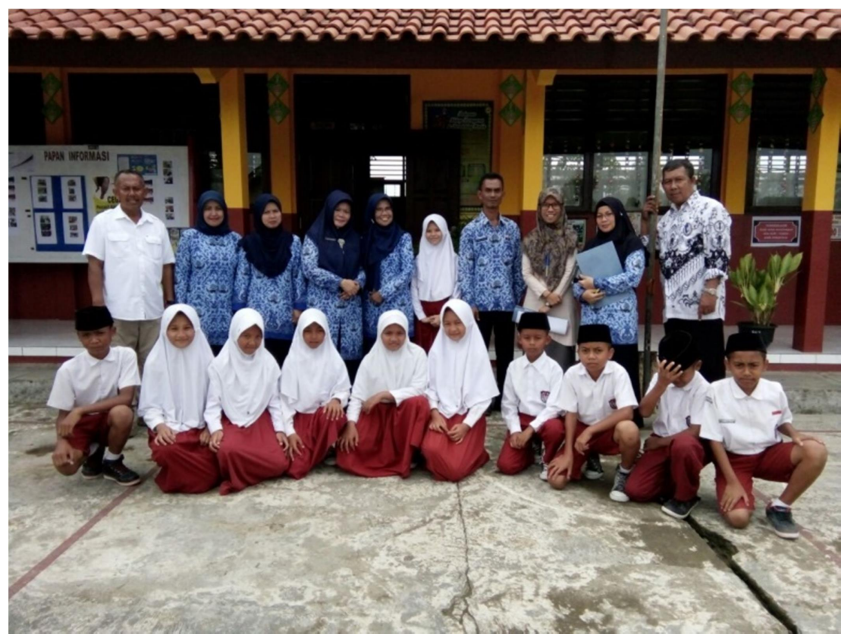

Gambar 5. Dokumentasi pasca diskusi dan evaluasi hasil pemeriksaan dan penilaian sekolah sehat 